U.S. DEPARTMENT OF HEALTH AND HUMAN SERVICES

CENTER FOR DISEASE CONTROL

NATIONAL INSTITUTE FOR OCCUPATIONAL SAFETY AND HEALTH

CINCINNAII, OHIO 45226

HEALTH HAZARD EVALUATION REPORT

HE 79-145-718

ST. JOSEPH HOSPITAL DENVER, COLORADO

\title{
JLY 1980
}

\section{SUMMARY}

In September 1979 the National Institute for Occupational Safety and Health (NIOSH) received a request to evaluate exposures to nitrous oxide, ethrane, and halothane in the Department of Surgery at St. Joseph Hospital, Denver, Colorado (Standard Industrial Classification 8070). Breathing zone and general room air samples were taken on nurses and anesthesiologists for nitrous oxide, ethrane, and halothane. All the anesthesiologists' equipment was monitored during surgical procedures for leakage. This monitoring was done by portable infra-red analyzer. $A$ medical history was taken on all surgical personnel who participated in the study.

Twenty-one of 28 ethrane air samples (75\%) exceeded the NIOSH exaluation criteria. Ethrane concentrations ranged from less than $0.01 \mathrm{mg} / \mathrm{M}^{3}$ to $14.0 \mathrm{mg} / \mathrm{M}^{3}$. None of the 28 halothane air samples exceeded the NIOSH evaluation criteria. Values ranged from less than $0.01 \mathrm{mg} / \mathrm{M}^{3}$ to 0.2 $\mathrm{mg} / \mathrm{M}^{3}$. Nitrous oxide breathing zone air samples exceeded the NIOSH evaluation criteria in approximately $25 \%$ of the samples taken.

Of the data collected, questionnaires were received from these respondents: 5 anesthesiologists, 62 of 63 (98.4\%) operating room staff (45 registered nurses, 17 other) and 18 of $19(94.7 \%)$ recovery room staff (14 registered nurses, 4 other).

Forty-six percent of the respondents reported one or more acute symptons (fatigue 32\%; headache 22\%; dizziness/lightheadedness $5 \%$; nausea $5 \%$; drowsiness $1 \%$, cough and skin irritation 5\%). Thirteen females reported menstrual or related irregularities. Five reported kidney disease history (nephrectomy, pyelonephritis, kidney stone) and four reported liver disease history. Of 49 reported pregnancies, two stillbirths and five miscarriages were reported. Analysis of the data for the group with acute symptoms versus those without symptoms revealed no significant differences by age, smoking status, job duration, and operating room shift exposures. 
Health Hazard Evaluation Report No. 79-145, Page 2

Analysis by job specific rates revealed either no significant differences or numbers too small for analysis. Analysis of reproductive effects revealed numbers too small for accurate evaluation. However, the number of miscarries observed were less than the number expected using rates reported by Cohen, et al. (Reference 1)

On the basis of the environmental and epidemiological data, it was concluded that a health hazard existed in the operating rooms at Saint Joseph Hospital from overexposures to ethrane and nitrous oxide. Recommendations on work practices and ventilation necessary to control these hazards are included on page 6 of this report.

II. INTRODUCTION

NIOSH received a request in September 1979 for a health hazard evaluation from the Department of Surgery at St. Joseph Hospital, Denver, Colorado, to evaluate waste anesthetic gas exposure in their operating rooms.l An environmental and epidemiological survey was conducted on November 27-28, 1979, to evaluate potential overexposures. Results of the survey was discussed with the requestor soon after receiving the laboratory results and the epidemiological data in April 1980.

\section{BACKGROUND}

The operating room department of St. Joseph Hospital is located on the first floor of the hospital with 14 operating rooms situated off two main corridors. Twelve operating rooms were in use the dates of the evaluation survey. The department averages 40 operations per day Monday through Friday and 12-18 operations on Saturday. The types of surgery conducted are listed in Table 1. Surgical patients are held in a pre-op room where they are premedicated just prior to surgery. They are then transported to an operating room and then post surgery to a recovery room. Post-operative patients are attended to in an open ward room by recovery room registered nurses and aides until coming out of anesthesia.

Staffing consists of approximately 63 nurses for the operating room department and 19 nurses for the recovery room. Job turnover of the clinical nursing staff is $15 \%$ per annum which is reported to be low for the Denver area. Work weeks alternate with a 5 day Monday through Friday/2 day off work-week and a Monday through Saturday work-week with Sunday plus one non-Saturday day off. The day shift runs 7 A.M. to 3:30 P.M.; nine registered nurses work four 10-hour days which run 7 A.M. to 5:30 P.M. There is also an evening shift that begins at 2:30 P.M.

ISection $20(a)(6)$ of the Occupational Safety and Health Act of 1970, 19 U.S.C. $669(a)(6)$, authorizes the Secretary of Health, Education, and Welfare, following a written request by any employer or authorized representative to employees, to determine whether any substance normally found in the place of employment has potentially toxic effects in such concentrations as used or found. 
Health Hazard Evaluation Report No. 79-145, Page 3

Anesthesiologists and surgeons are from a number of different practice groups and are in and out of the department. All anesthesiologists' equipment was in good repair and all were using nitrous oxide, ethrane, and halotane. Low flow anesthesiology (less than two liters per minute) was practiced by a majority of the anesthesiologists.

IV. METHODS AND MATERIALS

A. Environmental

Nitrous oxide samples were collected in 20 liter mylar bags using a vacuum pump operated at 300 cubic centimeters (cc) per minute. These samples were analyzed immediately on the surgical floor by infrared spectrometry using a Wilks Miran IA with a sensitivity of 5 ppm. Instrument settings were wave length 4.47 microns, path length 5.25 meters, and slit width 0.5 milliters $(\mathrm{mm})$. Halothane and ethrane samples were collected on charcoal tubes using vacuum pumps operated at $200 \mathrm{cc}$ per minute. Analysis of these samples was performed using gas chromatography and P\&CAM Method No. 127. Breathing zone air samples of operating room personnel were collected during each surgical procedure for the above anesthetic gases.

B. Epidemiological

A self-administered questionnaire was used to survey the operating and recovery room personnel. Non-respondents were mailed questionnaires for completion. This questionnaire was directed towards work-related illnesses of the kidney and liver. Questions were also asked relating to spontaneous abortions, fertility, fatigue, nausea, and dermatitis.

V. EVALUATION CRITERIA

A. Environmental

The source of criteria used to assess workroom concentrations of air contaminants was the NIOSH Criteria for a Recommended Standard for Occupational Exposure... Occupational Exposure to Waste Anesthetic Gases and Vapors. (Reference 2)

\section{Permissible Exposure Limits 8-Hour Time-Weighted Exposure Basis (ppm)}

Nitrous Oxide.............

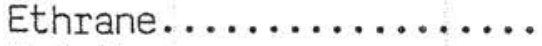
Halothane...............
25.0 (NIOSH)
0.5 (NIOSH
$0.5(\mathrm{NIOSH})$

ppm = parts of vapor or air per million parts of contaminated air

Occupational health standards are established at levels designed to protect individuals occupationally exposed to toxic substances on an 8-hour per day, 40-hour per week basis over a normal working lifetime. 
Health Hazard Evaluation Report No. 79-145, Page 4

B. Toxicological

In the NIOSH criteria document for a recommended standard for occupational exposure to anesthetic gases, NIOSH states: "Current scientific evidence obtained from human and animal studies suggests that chronic exposure to anesthetic gases increases the risk of both spontaneous abortion among female workers and congential abnormalities in the offspring of females workers and the wives of male workers. Risks of hepatic and renal diseases are also increased among exposed personnel. In addition, physiological function may be impaired. A few studies have suggested increased risk of cancer. Effects on the central nervous system due to acute exposures of anesthetic gases have been associated with headaches, nausea, fatigue, irritability, etc." Control procedures and work practices presented in that document, however, should prevent the effects caused by acute exposure and significantly reduce the risk associated with long-term, low level exposure. A dose response relationship for halogenated anesthetic toxicity has not been defined. (Reference 2)

That same NIOSH publication recommends maximum exposures to $25 \mathrm{ppm}$ nitrous oxide (eight-hour time-weighted average) and 2 ppm halogenated anesthetic when used alone, or $0.5 \mathrm{ppm}$ when used with nitrous oxide. These recommendations are based upon available technology in reducing waste anesthetic gas levels.

Reports by Vaisman (Reference 3) and Askrong and Harvald (Reference 4) were among the first to identify increased incidence of spontaneous abortion in women exposed to anesthetic gases and in wives of men exposed to anesthetic gases. Results of a more recent and comprehensive nationwide survey of occupational disease among operating personnel were published in 1974 by the American Society of Anesthesiologists (ASA). (Reference 1) The results of this study indicate "that female members of the operating room-exposed group were subject to increase risks of spontaneous abortion, congenital abnormalities in their children, cancer and hepatic and renal. disease. This increased risk of congential abnormalities was also present among the unexposed wives of male operating room personnel. No increase in cancer was found among the exposed males, but an increased incidence of hepatic disease similar to that in the female was found."

While several investigators have reported increased rates of resorption in animals, particularly rats, most of these studies involved concentrations of anesthetic gases well above the levels found in occupational exposure. One investigator (Reference 5) showed increased fetal death rates in two groups of rats following exposure of 1,000 and 100 ppm of nitrous oxide. Doenicke, et al., (Reference 6) concluded from their study of anesthetized pregnant rats that halothane demonstrates an abortive effect directly proportional to the concentration inhaled, again referring to anesthetic concentrations; but nitrous oxide does not produce an abortive effect. Bruce (Reference 7) reports no significant difference, including implantations and resorptions per pregnancy, in his exposure of rats to $16 \mathrm{ppm}$ halothane. 
Health Hazard Evaluation Report No. 79-145, Page 5

Several epidemiological studies that indicate increased spontaneous abortions also indicate an increased rate of congenital abnormalities. The ASA study (Reference 1) (as well as surveys by Knill-Jones, et al., (Reference 8) and Corbett, et. al. (Reference 9) indicated an increased rate of congenital abnormalities in children of women with occupational exposures to anesthetic gases and to wives of men with similar exposures. While most animal exposure studies have been conducted at anesthetic levels, one study (References 10, 11, 12) indicated liver, kidney, and brain tissue changes in pups born to rats exposed to sub-anesthetic concentrations of halothane during pregnancy.

The same epidemiological and toxicological studies that indicated an increase in spontaneous abortion and congenital abnormalities also indicated an increase in liver and kidney abornmalities. This increase, however, was less pronounced in both rate and severity.

In a study published by NIOSH (Reference 13), "nitrous oxide and halothane in respective concentrations as low as $50 \mathrm{ppm}$ and $1.0 \mathrm{ppm}$ caused measurable decrements in performance on some psychological tests taken by healthy male graduate students. Nitrous oxide alone caused similar effects. The functions apparently most sensitive to these low concentrations on anesthetics were visual perception, immediate memory, and a combination of perception, cognition, and motor responses required in a task of divided attention to simultaneous visual and auditory stimuli." Headache, fatigue, irritability, and disturbance, of sleep have also been reported (References 2, 14); and damage to cerebral cortical neurons has been seen in rats after sub-anesthetic exposure to halothane, (Reference 15) Quimby, et al., (Reference 16) reported permanent learning deficits in rats exposed to anesthetic concentrations of halothane during early development (from conception).

Mortality and epidemiological studies have raised the questions of possible carcinogenicity of anesthetic gases, but sufficient data are lacking to list nitrous oxide, halothane, or ethrane as suspected carcinogens.

Literature reviews regarding halothane (References 17, 18, 10, 20) indicate the most widely accepted mechanism of bio-transformation is the production of trifluoroacetic acid with resulting urinary excretion of trifluoroacetic acid and bromide. The literature regarding enflurane (References 21,22 ) does not indicate any one accepted mechanism, but increased serum and urinary fluoride levels were found in patients receiving enflurance anesthesia. While epidemiological and toxicological studies have indicated several symptoms apparently related to sub-anesthetic exposure to anesthetic gases, no cause and effect relationship has yet been shown.

A mail survey of 30,650 dentists and 30,547 chairside assistants grouped according to occupational exposure to inhalation anesthetic/sedatives in the dental operatory indicated increased general health problems and reproductive difficulties among anesthetic-exposed respondents. For heavily anesthetic-exposed male dentists, the increase in liver disease was 1.9-fold, kidney disease 1.2-fold, and neurological disease 1.9-fold. For wives of heavily 
Health Hazard Evaluation Report No. 79-145, Page 6

anesthetic-exposed male dentists the increase in spontaneous abortion rate was 1.5-fold. Among heavily anesthetic-exposed female chairside assistants, the increase in liver disease was 1.6-fold, kidney disease 1.7-fold and neurological disease 2.8-fold. The increase in spontaneous abortion rate among heavily exposed assistants was 2.3-fold. Cancer rates in women heavily exposed to inhalation anesthetics were increased 1.5-fold but this finding was only borderline significant $(P=0.06)$. Separate analysis of the data for disease rates and birth difficulties by type of inhalation anesthetic indicates that in both dentists and chairside assistants chronic exposure to nitrous oxide alone is associated with an increase rate of adverse response. (Reference 23) It would not be correct to extrapolate nitrous oxide epidemiological data taken on dentists and dental assistants to surgical operations. Dentists and their assistants are much closer to their work and are breathing higher concentrations than surgeons, scrub nurses, and anesthesiologists.

\section{RESULTS}

A. Environmental Results

Twenty-one of 28 (75\%) of the ethrane breathing zone air samples exceeded the NIOSH evaluation criteria. Ethrane concentrations ranged from less than $0.01 \mathrm{mg} / \mathrm{M}^{3}$ to $14.0 \mathrm{mg} / \mathrm{M}^{3}$. None of the 28 halothane environmental samples exceeded the NIOSH evaluation criteria. Overexposures to nitrous oxide were observed in approximately $25 \%$ of the samples taken. These operating rooms have at least 15 air changes per hour. Ventilation was adequate. High exposures were due to leaks in the anesthetic cart and at the mask of the patient. Results may be reviewed in Tables 2 and 3 . Scavenging equipment was present on all anesthetic carts. This system was working correctly as evidenced by periodic checks with a portable monitoring system.

B. Epidemiological Results

The findings in this cross-sectional study did not establish a strong association of acute symptom occurrence with operating room anesthetic gas exposure (i.e. operating room shift duration, operating room job duration). Prevalence of symptoms was approximately comparable for all job categories. The numbers in this survey are relatively small and would not be sensitive to small differences. The occurence of symptoms (i.e. fatigue, headache) might be explained by the general occurrence of these symptoms or more likely to the demands of the job descriptions of these persons, e.g. standing on feet for long periods of time. This limited study could not demonstrate any excess of chronic disease or adverse fertility effects in this worker population. Skin irritation was mentioned by five respondents and in some cases was associated with "scrubbing" and/or using Betadine. Since Betadine contains iodine, hypersensitivity to iodine may occur to susceptible individuals. Epidemiological data may be reviewed in Tables 4, 5, and 6 . 
Health Hazard Evaluation Report No. 79-145, Page 7

VII. CONCLUSIONS

Based on the environmental and epidemiological data, a health hazard did exist from overexposures to ethrane and nitrous oxide.

VIII. RECOMMENDATIONS

1. All workers should have annual physical examinations.

2. Any worker experiencing skin irritation associated with "scrubbing" with Betadine should use an alternative disinfecting agent to reduce the likelihood of sensitization.

3. Anesthesiologists should check slip connections and high pressure nitrous oxide connections since these are areas where high concentrations were obseved.

IX. REFERENCES

1. Cohen, E.N., et al, Ad Hoc Committee on the Effect of Trace Anesthetics on the Health of Operating Room Personnel: Occupational Disease Among Operating Room Personnel: A National Study. Anesthesiology 41:321-340, 1974.

2. Criteria for a Recommended Standard... Occupational Exposure to Waste Anesthetic Gases and Vapors. DHEW (NIOSH) Publication No. 77-140, 1977, $194 \mathrm{pp}$.

3. Vaisman, A.I. (Working conditions in surgery and their effect on the health of anesthesiologists). Eksp Khir Anest 3:44-49, 1967 (Rus).

4. Adkrog, V., and Harvald, B. (Teratogenic effect of inhalation anesthetics). Nord Med 83:498-504, 1970.

5. Corbett, T.H., Cornell, R.G., Endres, J.L., and Millard, R.I. Effects of Low Concentrations of Nitrous Oxide on Rat Pregnancy. Anesthesiology 39:299-301, 1973.

6. Doenicke, A., Wittmann, R., Heinrich, H., and Pausch, H. (Abortive effect of halothane). Anesth Analg (Paris) 32:47-51, 1975 (Fre).

7. Bruce, D.L. Murine Fetility Unaffected by Traces of Halothane. Anesthesiology 38:473-77, 1973.

8. Knill-Jones, R.P., Moir, D.D., Rodrigues, L.V., and Spence A.A. Anesthetic Practice and Pregnancy--Controlled Survey.

9. Corbett, T.H., Cornell, R.G., Lieding, K., and Endres, J.L. Incidence of Cancer Among - Michigan Nurse-Anesthetists. Anesthesiology 41:34-44, 1974.

10. Chang, L.W., Lee, Y.K., Dudley, A.W., Jr., and Katz, J. Ultrastructural Evidence of the Hepatotoxic Effect of Halothane in Rats Following In-Utero Exposure. Can Anaesth Soc $J$. 22:330-37, 1975. 
Health Hazard Evaluation Report No. 79-145, Page 8

11. Chang, L.W., Dudley, A.W., Jr., Lee, Y.K., and Katz, J. Ultrastructural Studies on the Pathological Changes in the Neonatal Kidney Following In-Utero Exposure to Halothane. Environ. Res 10:174-89., 1975.

12. Chang, L.W., Dudley, A.W., Jr., Katz, J., and Martin, A.H. Nervous System Development Following In-Utero Exposure to Trace Amounts of Halothane. Teratology 9:A-15, 1974.

13. Bruce, D.L., and Bach, M.H. Trace Effects of Anesthetic Gases on Behavioral Performance of Operating Room Personnel. HEW Publication No. NIOSH 76-169, 1976, 33 pp.

14. Uhlirova, A., and Pokorny, J. (Results of questionnaire survey of health damage to anesthesiologists). Rozhl Chir 53:761-70, 1976 (Cze).

15. Chang, L.W., Dudley, A.W., Jr., Lee, Y.K., and Katz, J. Ultrastructural Changes in the Nervous System After Chronic Exposure to Halothane. Exp Neurol 45:209-19, 1974.

16. Quimby, K.L., Aschkenase, L.H., Bowman, R.E., Katz, J., and Chang, L.W. Enduring Learning Deficits and Cerebral Synaptic Malformation From Exposure to Ten Parts of Halothane Per Million. Science 185:625-27, 1974.

17. Rehder, K., and Sessler, A.D. Biotransformation of Halothane. Int Anesthesiol Clin 12:41-53, 1974.

18. Sawyer, D., and Eger, E., II. Hepatic Metabolism of Aalothane. Int Anesthesiol Clin 12:55-62, 1974.

19. Cascorbi, H.F. Factors Causing Differences in Halothane Biotransformtion. Int Anesthesiol Clin 12:63-71, 1974.

20. Van Dyke, R.A. Biotransformation of Volatile Anesthetics With Spepcial Emphasis on the Role of Metabolism in the Toxicity of Anesthetics. Can Anesth Soc J 20:21-33, 1973.

21. Mazze, R.I., and Cousins, M.J. Biotransformation of Methoxyflurane. Int Anesthesiol Clin 12:93-105, 1974.

22. Cousins, M.D., and Mazze, R.I. Biotransformation of Enflurane (Ethrane) and Isoflurane (Forane). Int Anesthesiol Clin 12:111-119, 1974.

23. Cohen, E. N., et al, Occupational Disease in Dentistry and Exposure to Anesthetic Gases 1980. This research supported by the National Institutes of Health $\mathrm{OH}-00775$, and a grant in aid from the American Dental Association. 
X. AUTHORSHIP AND ACKNOWLEDGMENTS

Report Prepared By:

Evaluation Assistance:

Originating office:

Report Typed By:
Bobby J. Gunter, Ph.D.

Regional Industrial Hygienist

NIOSH - Region VIII

Denver, Colorado

Arthur S. Watanabe, Pharm.D.

Medical Investigator

Medical Section, Hazard Evaluation and

Technical Assistance Branch

NIOSH, Cincinnati, Ohio

G. Edward Burroughs

Richard $\mathrm{H}$. Patnode

Industrial Hygienists

Industrial Hygiene Section, HETAB

NIOSH, Cincinnati, Ohio

Hazard Evaluation and Technical Assistance Branch (HETAB)

Division of Surveillance, Hazard

Evaluations, and Field Studies (DSHEFS)

NIOSH, Cincinnati, Ohio

Marilyn K. Schulenberg

NIOSH - Region VIII

Denver, Colorado

XI. DISTRIBUTION AND AVAILABILITY

Copies of this determination report are currently available upon request from NIOSH, Division of Technical Service, Information Resources and Dissemination Section, 4676 Columbia Parkway, Cincinnati, Ohio 45226. After 90 days the report will be available through the National Technical Information Service (NTIS), Springfield, virginia. Information regarding its availability through NTIS can be obtained from NIOSH, Publications Office, at the Cincinnati address.

Copies of this report have been sent to:

1. St. Joseph Hospital.

2. U.S. Department of Labor/OSHA - Region VIII.

3. NIOSH - Region VIII.

4. Colorado Department of Health

5. State Designated Agency

For the purpose of informing all employees, a copy of this report shall be posted in a prominent place accessible to the employees for a period of 30 calendar days. 
Health Hazard Evaluation Report No. 79-145, Page 10

\section{TABLE 1}

Types of Surgery (percent)

St. Joseph Hospital

Denver, Colorado

$\begin{array}{lc}\text { Orthopedic } & 27.8 \% \\ \text { General } & 24.7 \% \\ \text { Gynecology } & 13.6 \% \\ \text { Cardiovascular } & 12.2 \% \\ \text { Urology } & 8.8 \% \\ \text { Neurology } & 4.0 \% \\ \text { Plastic } & 4.0 \% \\ \text { Opthalmology } & 2.5 \% \\ \text { Otolaryngology } & 2.2 \%\end{array}$


Health Hazard Evaluation Report No. 79-145, Page 11

TABLE 2

Breathing Zone and General Room Air Concentrations of Halothane and Ethrane

St. Joseph Hospital

Denver, Colorado

November 27-28, 1979

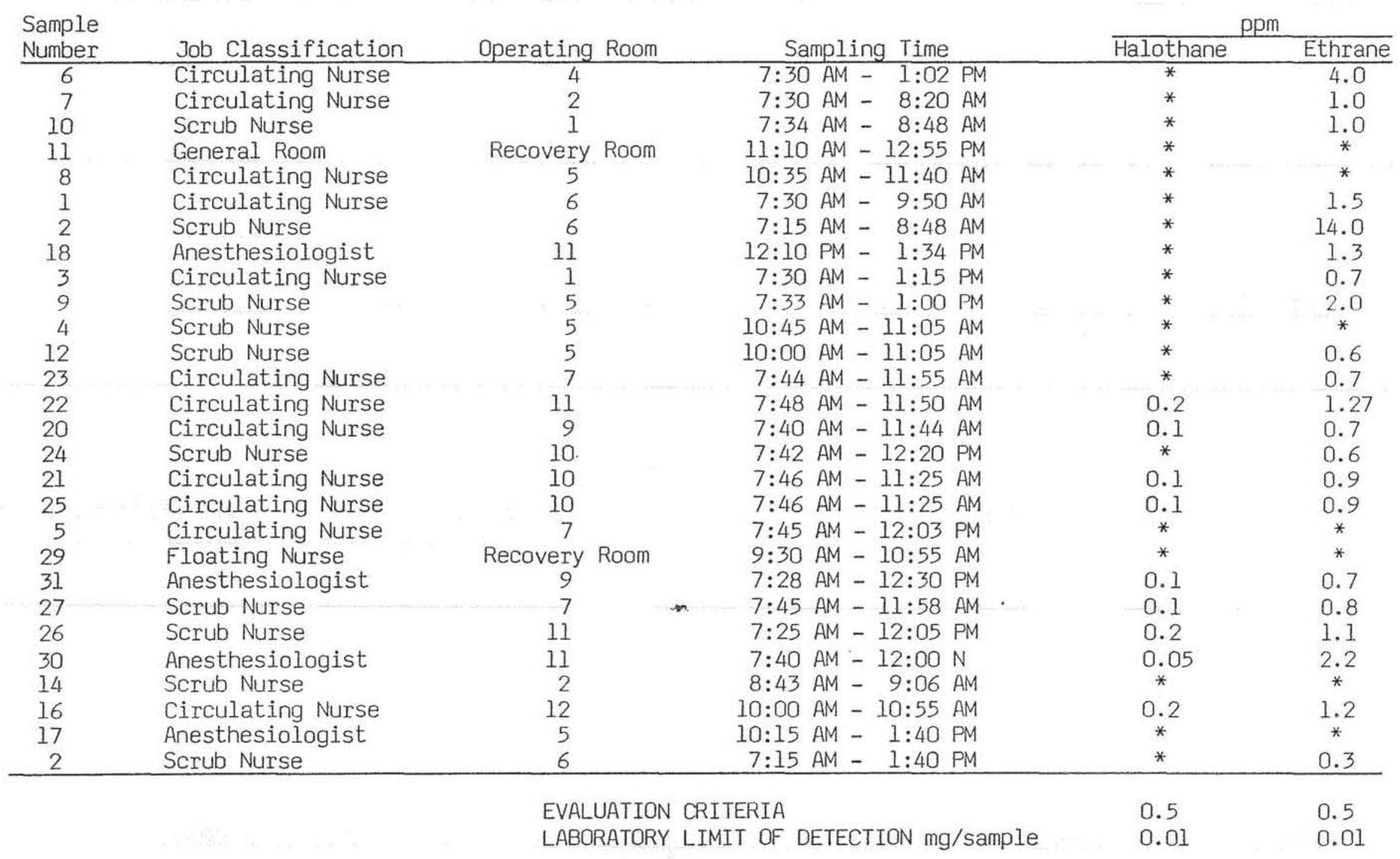


Health Hazard Evaluation Report No. 79-145, Page 12

\section{TABLE 3}

Breathing Zone and General Room Air Concentrations of Nitrous Oxide

St. Joseph Hospital

Denver, Colorado

NOVENBER 27, 1979

Scrub Nurse

Operating Room 4

Scrub Nurse

TOTAL MEAN

Scrub Nurse

Operating Room 7

Circulating Nurse

22

Scrub Nurse

44

Scrub Nurse

22

Scrub Nurse

31

Scrub Nurse

TOTAL MEAN

SCRUB NURSE MEAN

12

CIRCULATING NURSE MEAN

4

225

44

Anesthesiologist
Scrub Nurse
Circulating Nurse
Anesthesiologist
Scrub Nurse
Anesthesiologist
TOTAL MEAN
SCRUB NURSE MEAN
CIRCULATING NURSE MEAN
ANESTHESIOLOGIST MEAN

Operating Room 9

13

16

19

22

22

14

17.7

19

19

16.3

Circulating Nurse

Operating Room 10

Scrub Nurse

Circulating Nurse

Scrub Nurse

Circulating Nurse

Scrub Nurse

12

Circulating Nurse

12

TOTAL MEAN

14

CIRCULATING NURSE MEAN

15.9

SCRUB NURSE MEAN

15 
Health Hazard Evaluation Report No. 79-145, Page 13

TABLE 3 (continued)

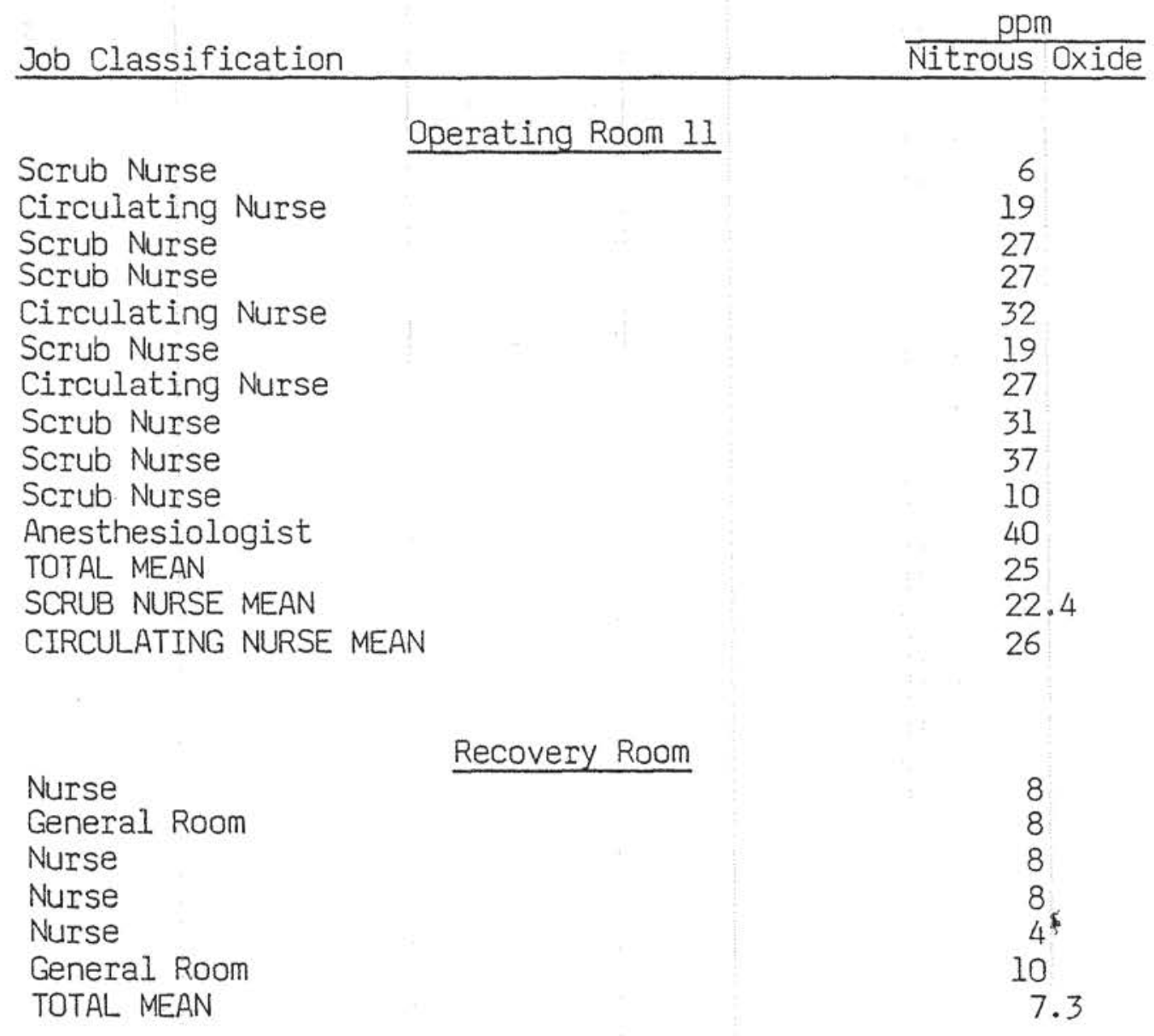

NOVEMBER 28,1979

Scrub Nurse

Operating Room 1

Scrub Nurse

Circulating Nurse

Circulating Nurse

Scrub Nurse

Circulating Nurse

TOTAL MEAN

SCRUB NURSE MEAN

CIRCULATING NURSE MEAN

10

10

230

4

6

45.0

10

80

31

22

10

21 
Health Hazard Evaluation Report No. 79-145, Page 14

TABLE 3 (continued)

Job Classification

Nitrous Oxide

Circulating Nurse

Scrub Nurse

TOTAL MEAN

12

Operating Room 3

Nurse Anesthetist

Operating Room 4

Circulating Nurse

14

19

Circulating Nurse

Circulating Nurse

Circulating Nurse

14

Scrub Nurse

12

Nurse Anesthetist

210

Circulating Nurse

12

Nurse Anesthetist

Nurse Anesthetist

7

Scrub Nurse

5

Circulating Nurse

16

Nurse Anesthetist

210

TOTAL MEAN

NURSE ANESTHETIST MEAN

SCRUB NURSE MEAN

27

CIRCULATING NURSE MEAN

45.8

52.6

$28^{*}$

50.7

Circulating Nurse

Operating Room 5

Anesthesiologist

19

Scrub Nurse

10

Scrub Nurse

19

Scrub Nurse

31

Circulating Nurse

19

Scrub Nurse

31

Circulating Nurse

22

Scrub Nurse

12

Circulating Nurse

16

TOTAL MEAN

2

CIRCULATING NURSE MEAN

18.1

SCRUB NURSE MEAN

16

ANESTHESIOLOGIST MEAN

21.4

10

Circulating Nurse

Operating Room 6 
Health Hazard Evaluation Report No. 79-145, Page 15

TABLE 3 (continued)

\begin{tabular}{lcc} 
Job Classification & & ppm \\
\hline & Operating Room 12 & Nitrous Oxide \\
Scrub Nurse & & 12 \\
Scrub Nurse & 16 \\
Scrub Nurse & 12 \\
TOTAL MEAN & & \\
& & \\
General Room & Recovery Room & 4 \\
General Room & 10 \\
General Room & 19 \\
TOTAL MEAN & & 14
\end{tabular}


Health Hazard Evaluation Report No. 79-145, Page 16

TABLE 4

Population Characteristics of Operating Room Personnel

Saint Joseph Hospital (SJH)

Denver, Colorado

November 26-28, 1979

\begin{tabular}{lll}
\multicolumn{2}{c}{ EMPLOYEES } & \multicolumn{2}{c}{$\begin{array}{c}\text { SJH } \\
\text { NO. MALE FEMALE }\end{array}$} & $\frac{\text { JOB DURATION (YIS.) }}{X \text { (S.D.) }}$ & SMOKERS \\
\hline
\end{tabular}

1. OPERATING ROOM 62
a. $\mathrm{RN}$
$45 \quad 2$
43
$33.9(7.1)$
5.7
$(5.7)$
14
b. Non-RN
17
611
$29.7(10.4)$
6.9
(6.9)
7
Mgr.
Techs.
11
Assists. 2
Orderly

3

2. ANESTHESIOLOGY

$\begin{array}{llllllll}5 & 5 & 0 & 40 & (7.3) & 13.8 & (8.7) & 1\end{array}$

3. RECOVERY ROOM 18

\begin{tabular}{lccccccc} 
a. RN & 14 & 0 & 14 & $33.8(5.4)$ & 4.6 & $(4.0)$ & 5 \\
b. Non-RN & 4 & 3 & 1 & $25.3(6.0)$ & 3.9 & $(6.5)$ & 1 \\
\hline $\mathrm{AL}$ & 85 & 16 & 69 & $33.1(7.9)$ & 6.9 & $(5.3)$ & 28
\end{tabular}

$\bar{X}=$ Mean

S.D. = Standard Deviation 
Health Hazard Evaluation Report No. 79-145, Page 17

\section{TABLE 5}

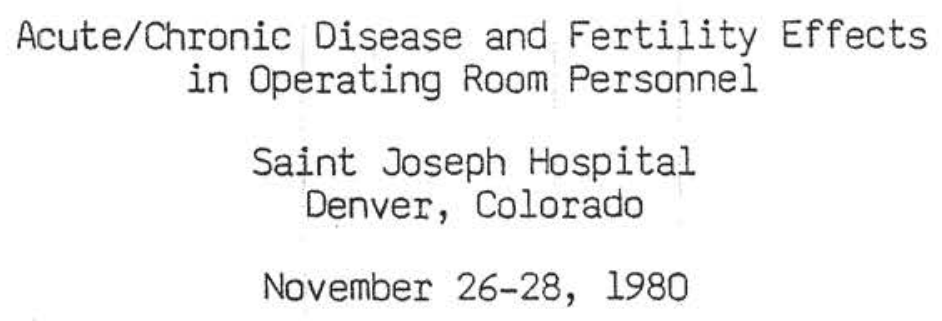

\begin{tabular}{|c|c|c|c|c|c|}
\hline & & & & & 1 \\
\hline icute Sx & Liver & Kidney & 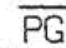 & $\overline{L B}$ & \\
\hline
\end{tabular}

1. OPERATING ROOM

$\begin{array}{lrlllllll}\text { RN } & 22(48.9 \%) & 4 & 2 & 19 & 14 & 0 & 2 & 3 \\ \text { Non-RN } & 7(41.2 \%) & 1 & 0 & 7 & 7 & 0 & 1 & 0\end{array}$

2. ANESTHESIOLOGY

$2(40 \%) \quad 0 \quad 1 \quad 138 \div 230$

3. RECOVERY ROOM

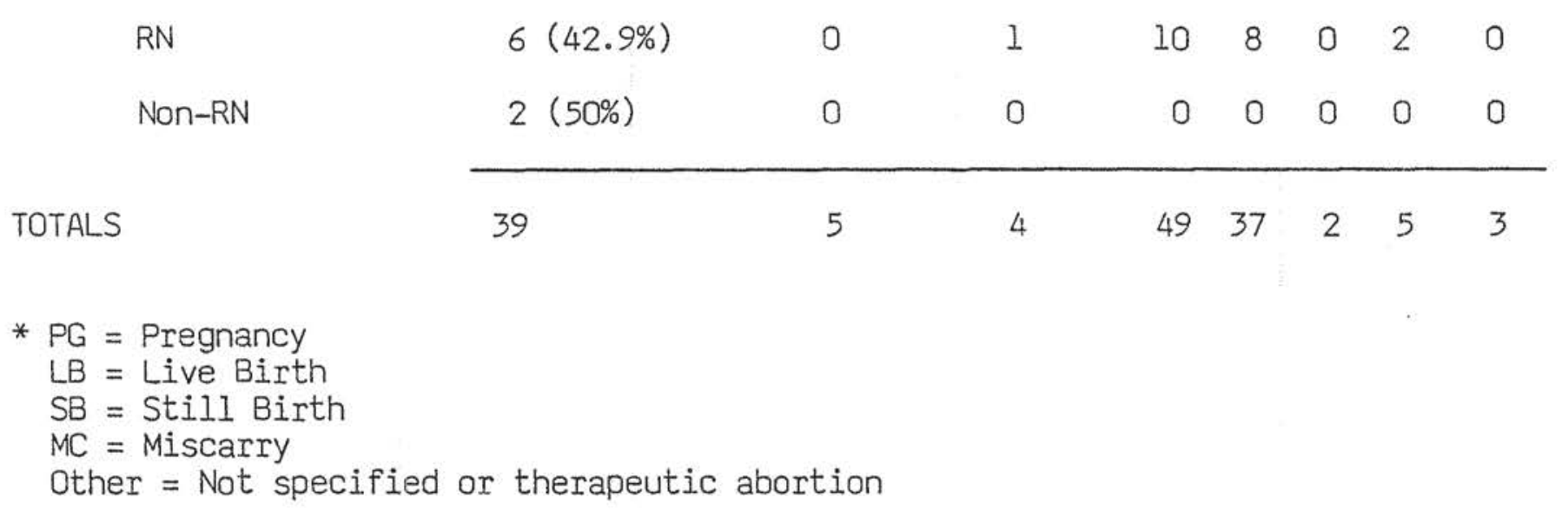


Health Hazard Evaluation Report No. 79-145, Page 18

TABLE 6

Types of Acute Symptoms in Operating Room Personnel

Saint Joseph Hospital

Denver, Colorado

November 25-28, 1979

Skin

HA LH/DZ Fatigue Nausea Irritation Other

1. OPERATING ROOM

$\begin{array}{lrrrrrr}\text { a. RN } & 14 & 2 & 13 & 3 & 3 & 0 \\ \text { b. Non-RN } & 2 & 1 & 3 & 1 & 2 & 0\end{array}$

2. ANESTHESIOLOGY

$\begin{array}{llllll}0 & 0 & 2 & 0 & 0 & 0\end{array}$

3. RECOVERY ROOM \&

$\begin{array}{lllllll}\text { a. } & \text { RN } & 0 & 1 & 4 & 1 & 0\end{array}$

b. Non-RN

$\begin{array}{lll}1 & 0 & 2\end{array}$

$0 \quad 0$

TOTALS

194

27

5

5

2

$H A=$ Headache

$\mathrm{LH} / \mathrm{DZ}$ = Lightheadedness/Dizziness 